\title{
Estimating organic carbon in soils from Gulyantsi Municipality, Pleven District
}

\section{Оценка на органичния въглерод в почви от община Гулянци, област Плевен}

\author{
Alexander Saraffov, Petko Bozhkov, Borislav Grigorov \\ Александър Сарафов, Петко Божков, Борислав Григоров
}

Sofia University “St. Kliment Ohridski”, Faculty of Geology and Geography, Department of Landscape Ecology and Environmental Protection, 15 Tsar Osvoboditel Blvd., 1504 Sofia; E-mails: saraffov@gea.uni-sofia.bg; borislav.g.grigorov@gmail.com; petko_bozhkov@abv.bg

\begin{abstract}
The aim of the present study is to evaluate soil organic carbon in Gulyantsi Municipality, Pleven District. The case study area of "Ulpia Eskus" Reserve was chosen for the research. The composition of soil organic substance of Arenosols + Fluvisols is distinguished by the use of a chemical analysis and the application of the Turin method. The results show a prevalence of humic acids over fulvic acids in the sampled soil profile.
\end{abstract}

Keywords: soil organic carbon, soil horizons, excavations.

Археологическият резерват „Улпия Ескус“ се намира в Чернополската низина, втората по големина крайдунавска низина в България, между приустиевите части на реките Искър на запад и Вит на изток. Във водоразделното ВитскоОсъмско равнище преобладава плоският платовиден монотонен релеф с най-висока точка (и за община Гулянци) - 203 m надморска височина. В тази по-висока част льосовите хоризонти залягат почти хоризонтално.

Преди изграждането на дигата по р. Дунав, в края на миналия век, големи участьци в низинната част са заливани и заблатявани. Преди това единствено високи пясъчни гредове са съществували като острови. Тектонски са причините, променили ерозионния базис на р. Дунав и започнали създаването на терасния комплекс преди формирането на льоса, който заема само високите тераси.

Проявилите се дефлационни процеси са формирали според Ninov (2009) в низината единия от четирите подтипа български пясъчни почви (ареносоли) в землищата на община Гулянци, създадени от ,подвижни и преотлагани от вятъра плейстоценски еолови пясъци“. В Чернопол- ската низина е най-голямата площ на асоциация на Arenosols + Fluvisols. Различава ги еднородността, по-голямото от 65\% съдържание сред ситнозема на пясъка и липсата на упльтняване. Върху тези безплодни почви вирее ракитовица или тамарикс, растение, понасящо и засолеността в почвената среда на низината. Доминираните от ракитовица (Tamarix ramosissima Ledeb.) храстови съобщества в местността Катината до с. Загражден са със статут на защитена местност, предвид започналото им изчезване след антропогенизирането на низината и залесяването с тополи.

На дълбочина 2 m в изследвания археологически участьк е установена керамика и е взета проба (№ 34, табл. 1) от веществения материал между фрагментите. В профила на тъмнооцветената техногенна почва има повече от 20 \% дребни до средни камъни, хоросан и каменна настилка от римския период в обема под първите $20 \mathrm{~cm}$. Опожаряване, ремонтиране и разрушаване на сградата са процеси, оставили следи от строителен материал. Kabakchieva \& Dragoev (2019) отбелязват, че през първата четвърт на IV в. каменният материал на зидовете е бил изваждан 
и преупотребяван за ново строителство. От естествения повърхностен пласт също бе взет материал за органичен анализ (проба № 29, табл. 1). В него няма артефакти и отговаря на критериите за диагностициране на хоризонт „Черник“ (от рус. чёрный), развит върху льосови отложения.

„Черник“ хоризонт притежават зонално проявените почви от референтна група с акумулация на органично вещество в повърхностни минерални хоризонти. Според определителя на цветовете на почвата (скалата на Munsell..., 2012), интензивността на осветеността (value) от бяло (10) до черно (1) съответства на $\leq 5$ в сухо и $\leq 3$ във влажно състояние и на наситеност на тона (chroma) $\leq 2$. Съдържанието на органичен въглерод, преизчислен в хумус по формулата C x 1,724 (Trendafilov, Popova, 2007), е над 1\%. Тази стойност също плавно намалява с удълбочаването като в конкретния случай за повърхностния хоризонт е оценено като средно (параметрични стойности между 1,81 и $3,1 \%$ хумус - вж. колонка 2 в табл. 1) според оценъчната скала, предложена от Gyurov \& Artinova (2015). Коефициентьт на спад на хумуса се увеличава на $2 \mathrm{~m}$ дълбочина в проба 34 до 1,7 пъти и е в долната част на референтните граници за карбонатни черноземи южно от река Дунав.

Качественият състав на хумуса при различните почви се определя от отношението на съдържанието на хуминовите киселини (ХК) към това на фулво киселините (ФК). Установеното количествено участие на ХК (Схк 0,38\%) към теглото на сухата почва в числителя и в \% от общото съдържание на органичния $\mathrm{C}$ в знаменателя (Схк $21,11 \%$ в изходната проба) показва преобладаване на ХК над това на ФК. Това вероятно се дължи на доминирането на житните треви с гъста коренова система. Определянето фракционния състав на хумуса бе извършен в Централна лаборатория на ИПАЗР „Никола Пушкаров“".

За оценка на степента на хумификация на органичното вещество, изразена чрез \% на ХК от общия органичен въглерод - 21,1\%, се използва класификацията на Artinova (2014). Според нея тя е много висока (над 20\%). Типът на хумуса, според отношението Схк/Сфк на количеството на ХК, изразено чрез участващия в тях органичен въглерод, към количеството на ФК- 2,92\%, е хуматен, когато е над 2,0 (по оценъчната скала на Gyurov \& Artinova, 2015). Формирането на този тип хумус вероятно се дължи на участието на органичното вещество на тревната растителност и карбонатната почвообразуваща скала, както се вижда и от данните в табл. 1. От резултатите става ясно, че на дълбочина от $2 \mathrm{~m} \mathrm{XK}$ напълно са свързани с алкалоземните елементи. Присъствието на $\mathrm{Ca}^{2+}$ в карбонатния веществен състав е предпоставка за осигуреност на плодородие чрез формирането на устойчиви Са-хумати при много високо съдържание на ХК, свързани с $\mathrm{Ca}$, в процент от общото количество $>80 \%$, достигащо до $100 \%$ (табл. 1).

Груповият състав на хумуса в табл. 1 описва сумите от екстрахиран въглерод (извлечен със смес от $0.1 \mathrm{M} \mathrm{Na}_{2} \mathrm{P}_{2} \mathrm{O}_{7}+0.1 \mathrm{M} \mathrm{NaOH}$ ) и не-

Таблий 1. Резултати от изследването на почвените проби

\begin{tabular}{|c|c|c|c|c|c|c|c|c|c|}
\hline \multirow{2}{*}{ 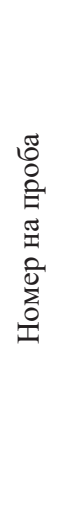 } & \multirow{2}{*}{ 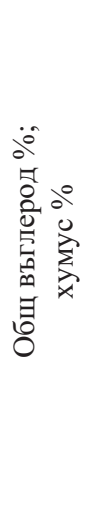 } & \multicolumn{3}{|c|}{$\begin{array}{c}\text { Органичен въглерод (\%); } \\
\text { екстрахиран с } \\
0.1 \mathrm{M} \mathrm{Na}_{2} \mathrm{P}_{2} \mathrm{O}_{7}+0.1 \mathrm{M} \mathrm{NaOH}\end{array}$} & \multirow{2}{*}{ ên } & \multicolumn{2}{|c|}{$\begin{array}{c}\text { Органичен въглерод (\%); } \\
\text { фракции на хуминовите } \\
\text { киселини }\end{array}$} & \multirow{2}{*}{ 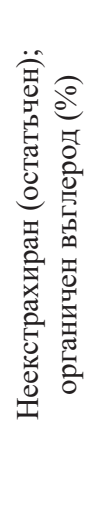 } & \multirow{2}{*}{ 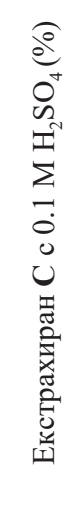 } \\
\hline & & общ & 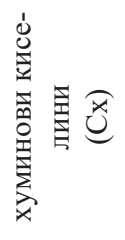 & 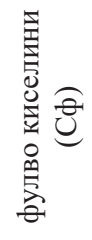 & & 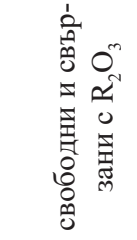 & 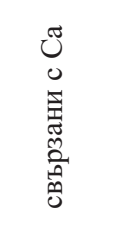 & & \\
\hline 29 & $\frac{1,80}{3,10}$ & $\frac{0,51}{28,33}$ & $\frac{0,38}{21,11}$ & $\frac{0,13}{7,22}$ & 2,92 & $\frac{0,08}{21,05}$ & $\frac{0,30}{78,95}$ & $\frac{1,29}{71,67}$ & $\frac{0,08}{17,78}$ \\
\hline 34 & $\frac{1,05}{1,81}$ & $\frac{0,31}{29,52}$ & $\frac{0,22}{20,95}$ & $\frac{0,09}{8,57}$ & 2,44 & 0,00 & 100,00 & $\frac{0,74}{70,48}$ & $\frac{0,04}{3,81}$ \\
\hline
\end{tabular}


екстрахиран такъв, останал в почвата въглерод. Съдържанието на последният не се различава съществено при двете проби (70,48\% и 71,67\%). По протежение на целия профил участието на фулвокиселини е незначително.

Картирани и диагностицирани са следните техносоли: Urbic (ub) (от лат. urbs, град) с хоризонт дълбок $\geq 20 \mathrm{~cm}$, съдържащ $\geq 20 \%$ артефакти, сред които $\geq 35 \%$ са строителни материали и остатъци от времето на функционирането на археологически обект „Улпия Ескус“ край с. Гиген.

Благодарности: Публикацията е част от дейността по проект със заглавие „Екосистемни/ ландшафтни услуги, предоставяни от Technosol в България“, финансиран от ФНИ на СУ „Св. Климент Охридски“" съгласно Договор № 80-10103/16.04.2020 г.

\section{Литература \\ References}

Gyurov, G., N. Artinova. 2015. Soil Science. Plovdiv, Intelexpert, 257 p. (in Bulgarian).

Kabakchieva, G., D. Dragoev. 2019. Excavations of the building with the 'ACHAEANS' mosaic in Ulpia Oescus. - Archaeological Discoveries and Excavations 2018, NAIM, Sofia, 224-227 (in Bulgarian with English abstract).

Munsell Soil-color Charts: With Genuine Munsell Color Chips. 2012. Grand Rapids, MI, Munsell Color, 68 p.

Ninov, N. 2009. Sandy soils (Arenosols) in Bulgaria. - Problems of Geography, 1, 16-26 (in Bulgarian with English abstract).

Artinova, N. 2014. Humus condition of soils in Bulgaria - In: Soil Organic Matter and Soil Fertility in Bulgaria. Sofia, Bulgarian Humic Substances Society (BHSS), 476 p. (in Bulgarian).

Trendafilov, K., R. Popova. 2007. Soil Science Exercise Manual. Plovdiv, Academ. Publishing House Agricultural Univ., 182 p. (in Bulgarian). 